\title{
Treatment of giardiasis in children : Randomized trial of rectal metronidazole versus oral tinidazole
}

\section{Vakkilainen, Svetlana}

2020-11

Vakkilainen, S , Nieminen , T , Björkbacka , S, Saavalainen-Hakala , T \& Salo , E 2020 , '

Treatment of giardiasis in children : Randomized trial of rectal metronidazole versus oral

tinidazole ' , Journal of Infection , vol. 81 , no. 5 , pp. 839-841 . https://doi.org/10.1016/j.jinf.2020.08.050

http://hdl.handle.net/10138/333871

https://doi.org/10.1016/j.jinf.2020.08.050

cc_by_nc_nd

acceptedVersion

Downloaded from Helda, University of Helsinki institutional repository.

This is an electronic reprint of the original article.

This reprint may differ from the original in pagination and typographic detail.

Please cite the original version. 


\title{
Treatment of giardiasis in children: Randomized trial of rectal metronidazole versus oral tinidazole
}

\author{
Svetlana Vakkilainen \\ Tea Nieminen \\ Susanna Björkbacka \\ Tarja Saavalainen-Hakala \\ Eeva Salo
}

New Children's Hospital, Pediatric Research Center, University of Helsinki and HUS Helsinki

University Hospital, Stenbäckinkatu 9, PL 347, 00290 Helsinki, Finland 


\section{Abstract}

3 Objectives: We investigated the efficacy, safety and acceptance of rectally administered 4 metronidazole for the treatment of giardiasis in children.

$5 \quad$ Patients and Methods: This study (ClinicalTrials.gov Identifier: NCT02942485) was an open-labeled

6 randomized comparison of a 3-day-course of rectal metronidazole and single-dose oral tinidazole in 7 children with giardiasis. Clinical cure was defined as the resolution of symptoms by day 10 post8 treatment. Microbiological eradication was assessed with stool enzyme immunoassay for 9 G.duodenalis antigen on day 7-10 post-treatment.

10 Results: The study was terminated due to the extremely slow enrollment. We describe the outcome 11 for six patients treated with rectal metronidazole and one patient treated with oral tinidazole. All 12 symptomatic patients (4/4) were clinically cured with rectal metronidazole. Microbiological 13 eradication was successful after the first treatment course in all tested patients (6/6), of whom five 14 were treated with rectal metronidazole and one with oral tinidazole. Side effects were reported in one 15 patient and were restricted to a single episode of loose stool after the third dose of rectal 16 metronidazole. The majority of caregivers (4/6) considered the administration of rectal metronidazole 17 relatively easy.

18 Conclusions: We provide a proof of principle for the efficacy of rectally administered metronidazole 19 in the treatment of giardiasis.

21 Key words: Giardia duodenalis, nitroimidazole, pediatric 
24 Funding: This research did not receive any specific grant from funding agencies in the public, 25 commercial, or not-for-profit sectors. All medicines for the study were covered by the Hospital for 26 Children and Adolescents, Helsinki University Hospital as a part of routine patient care. 
Zimmermann and colleagues, in this Journal, drew attention to potential changes in healthy microbiota caused by ingested antibiotics. [1] We conducted a clinical trial to evaluate the efficacy and safety of rectal metronidazole in the treatment of Giardia duodenalis (G.duodenalis) infection in 31 children.

A protozoan G.duodenalis infects small intestine of humans with the incubation period of 7-28 days. Infection can remain asymptomatic or present as diarrhea, abdominal pain or failure to thrive. In Nordic countries, including Finland, prevalence of giardiasis is $5.8 \%$ in symptomatic population.[2] A single positive stool enzyme immunoassay for G.duodenalis antigen provides a diagnostic sensitivity close to $100 \%$ and specificity of $>90 \%$.[3] Nitroimidazoles represent the drugs of choice for giardiasis, particularly single-dose oral tinidazole.[4] Side effects of nitroimidazoles are usually mild and self-limited, including abdominal pain, nausea, diarrhea, metallic/bitter taste, headache and dizziness.[4] However, oral administration of nitroimidazoles in children often proves difficult in the absence of palatable pediatric formulations. Rectal tinidazole had been historically used for giardiasis treatment in Finland until the drug became unavailable. Rectal metronidazole has demonstrated efficacy in the treatment of vaginal trichomoniasis [5] and in the prophylaxis of postoperative wound infections.[6,7] Rectal administration of metronidazole results in lower serum concentrations, necessitating higher dosage. $[8,9]$

This open-label trial (ClinicalTrials.gov Identifier: NCT02942485, registered on $24^{\text {th }}$ of October 2016) was conducted at the Children's Hospital, Helsinki University Hospital from 1.1.2017 to 1.11.2019. The study protocol was approved by the Institutional Ethic's Board (HUS/1065/2016) and by the Finnish Medicines Agency (FIMEA, KLnro 145/2016, EudraCT 2016-001938-96). The study was conducted in accordance with the Declaration of Helsinki and national and institutional standards. Informed consent was obtained from the caregivers and from patients aged $\geq 7$ years. 
authors then recruited the referred children whose clinical symptoms were compatible with giardiasis and whose stool samples tested positive for G.duodenalis in HUSLAB laboratory. Exclusion criteria were: 1) age $<6$ months or $>10$ years, 2) weight $<9.5 \mathrm{~kg}, 3)$ the absence of symptoms, and 4) coinfection with another intestinal pathogen. We assessed clinical response to treatment, side effects and parental acceptance of the formulation during interviews with patients/caregivers at primary visits and by phone at the follow-up.

We randomized patients at primary visits alternately into two groups by random allocation. Group 1 was treated with oral tinidazole (Fasigyn ${ }^{\circledR}$ ) at a single dose of $50 \mathrm{mg} / \mathrm{kg}$, maximum $2 \mathrm{~g} / \mathrm{dose}$. Group 2 was given rectal metronidazole (Flagyl ${ }^{\circledR}$ ) for three consecutive days at 500/1000/1500 $\mathrm{mg} / \mathrm{dose} /$ day for children weighing 10-14.9/15-29.9/30-44.9 $\mathrm{kg}$, respectively. The doses of rectal metronidazole were arbitrary derived from the maximum oral dose (two grams) in adults. The first dose of metronidazole was administered by research nurse and two subsequent doses by caregivers at home. Clinical cure was defined as the resolution of symptoms by day 10 post-treatment. Stool samples for enzyme immunoassay were collected on day 7-10 post-treatment. If patients did not clear the infection, Group 1 was re-treated by rectal metronidazole and Group 2 by oral tinidazole (crossover). We did not measure metronidazole serum concentrations.

The study was terminated due to the extremely slow patient enrollment: eight patients only have been referred and recruited during the two-year period (Figure 1). This may reflect the low prevalence of giardiasis in the City of Helsinki, the inefficient advertising, or the unwillingness of primary care practitioners to refer children with an easily treatable condition. At the final stage of data analysis we discovered that $6 / 8$ patients fulfilled one or more of the exclusion criteria. Four children were asymptomatic, and G.duodenalis was detected during their routine immigrant evaluation. Five patients were co-infected with other pathogens (Shigella spp and Campylobacter jejuni $(\mathrm{n}=1)$, Hymenolepis nana $(\mathrm{n}=1)$, Dientamoeba fragilis $(\mathrm{n}=1)$ and Blastocystis hominis $(\mathrm{n}=4))$. One asymptomatic patient was excluded from further analysis due to incomplete follow-up (language barrier). Thus, we next describe outcomes for six patients treated with rectal metronidazole and one 
patient treated with oral tinidazole (Table 1).

Median age of the patients at recruitment was 2.6 years (range 1.8-6.7 years). None had chronic illnesses or regular medications. All participants completed treatment without interruptions. Microbiological eradication was successful after the first treatment course in $6 / 6$ tested patients (five treated with rectal metronidazole and one with oral tinidazole). All four symptomatic patients were clinically cured with rectal metronidazole. For one of them (Patient 3), the follow-up stool sample was unavailable. This patient's diarrhea recurred seven weeks post-treatment, and G.duodenalis was again detected in stool sample, indicating either treatment failure or re-infection. The patient received oral tinidazole with no response. After treatment with mepacrine hydrochloride according to the institutional guidelines, G.duodenalis was eradicated and the child was clinically cured.

Side effects were reported in one patient as a single episode of loose stool after the third dose of rectal metronidazole. The caregivers were asked to rate the ease of administration of rectal metronidazole at home, according to the suggested scale (very difficult / difficult $(n=1) /$ relatively easy $(n=4)$ / easy / very easy $(n=1))$. All caregivers in the rectal metronidazole group, but not the caregiver of a child who had received oral tinidazole, would opt for the same treatment modality in future. These results demonstrate the high rate of acceptability of rectal metronidazole by caregivers. In conclusion, this is the first study evaluating the efficacy and safety of rectal metronidazole in children with giardiasis. We carefully planned the open-labeled randomized comparison study, which was, however, unsuccessful due to the insufficient recruitment rate. Therefore, our results are observational and call for further larger trials. Despite the small sample size, and thus the descriptive nature of the trial, this study provides encouraging preliminary data. We demonstrated clinical cure and microbiological eradication in $4 / 4$ and 5/5 patients with giardiasis, respectively, after a three-day course of rectally administered metronidazole. Our study provides proof-of-concept for rectal use of metronidazole in pediatric giardiasis. 


\section{Author contribution}

106 ES and SV designed the study. ES, TN, TSH, SB and SV recruited the patients and gathered the 107 clinical data. SV analyzed the data and drafted the manuscript. All authors contributed to the writing 108 of the manuscript and approved the final version. 


\section{References}

111 [1] Zimmermann P, Curtis N. The effect of antibiotics on the composition of the intestinal microbiota 112 - a systematic review. J Infect 2019 ; 79:471-89. doi: 10.1016/j.jinf.2019.10.008.

114 [2] Hörman A, Korpela H, Sutinen J, Wedel H, Hänninen ML. Meta-analysis in assessment of the 115 prevalence and annual incidence of Giardia spp. and Cryptosporidium spp. infections in humans in 116 the Nordic countries. Int J Parasitol 2004 ; 34:1337-46. https://doi.org/10.1016/j.ijpara.2004.08.009. 117

118 [3] Jahan N, Khatoon R, Ahmad S. A comparison of microscopy and enzyme linked immunosorbent 119 assay for diagnosis of Giardia lamblia in human faecal specimens. J Clin Diagn Res 2014 ; 8:DC04120 6. https://doi.org/10.7860/JCDR/2014/9484.5087.

[4] Ordóñez-Mena JM, McCarthy ND, Fanshawe TR. Comparative efficacy of drugs for treating giardiasis: a systematic update of the literature and network meta-analysis of randomized clinical trials. J Antimicrob Chemother 2018 ; 73:596-606. https://doi.org/10.1093/jac/dkx430.

[5] Panja SK. Treatment of trichomoniasis with metronidazole rectal suppositories. Br J Vener Dis $1982 ; 58: 257-8$. https://doi.org/10.1136/sti.58.4.257.

[6] McLean A, Ioannides-Demos L, Somogyi A, Tong N, Spicer J. Successful substitution of rectal metronidazole administration for intravenous use. Lancet $\mathbf{1 9 8 3} ;$ 1:41-3. https://doi.org/10.1016/s0140-6736(83)91573-8.

133 [7] de Boer CN, Thornton JG. Prophylactic short course rectal metronidazole for cesarean section. A 134 double-blind controlled trial of a simple low cost regimen. Int J Gynaecol Obstet 1989 ; 28:103-7. 
135 https://doi.org/10.1016/0020-7292(89)90468-2.

136

137 [8] Lau AH, Lam NP, Piscitelli SC, Wilkes L, Danziger LH. Clinical pharmacokinetics of 138 metronidazole and other nitroimidazole anti-infectives. Clinical Pharmacokinetics 1992;23:328-64.

139 https://doi.org/10.2165/00003088-199223050-00002.

140

141 [9] Mattila J, Männistö PT, Mäntylä R, Nykänen S, Lamminsivu U. Comparative pharmacokinetics

142 of metronidazole and tinidazole as influenced by administration route. Antimicrob Agents Chemother $1431983 ; 23: 721-5$. https://doi.org/10.1128/aac.23.5.721. 
Table 1. Summary of the clinical trial of rectal metronidazole compared with oral tinidazole in children with Giardia duodenalis infection.

\begin{tabular}{|c|c|c|c|c|c|c|}
\hline Patient & $\begin{array}{l}\text { Age group at } \\
\text { recruitment, } \\
\text { years }\end{array}$ & $\begin{array}{l}\text { Symptoms compatible } \\
\text { with giardiasis }\end{array}$ & Treatment group & $\begin{array}{l}\text { Clinical } \\
\text { cure }\end{array}$ & $\begin{array}{l}\text { Microbiological } \\
\text { eradication }\end{array}$ & Side effects \\
\hline 1 & $1-3$ & $\begin{array}{l}\text { abdominal pain, } \\
\text { flatulence }\end{array}$ & rectal metronidazole & yes & yes & no \\
\hline 2 & $1-3$ & $\begin{array}{l}\text { abdominal pain, } \\
\text { flatulence, intermittent } \\
\text { diarrhea }\end{array}$ & rectal metronidazole & yes & yes & $\begin{array}{l}\text { loose stool } \\
\text { once after the } \\
\text { third dose }\end{array}$ \\
\hline 3 & $1-3$ & $\begin{array}{l}\text { abdominal pain, diarrhea, } \\
\text { flatulence, weight loss }\end{array}$ & rectal metronidazole & yes & $\mathrm{n} / \mathrm{a}$ & no \\
\hline 4 & $1-3$ & none & rectal metronidazole & $\mathrm{n} / \mathrm{a}$ & yes & no \\
\hline 5 & $5-8$ & none & rectal metronidazole & $\mathrm{n} / \mathrm{a}$ & yes & no \\
\hline 6 & $1-3$ & intermittent diarrhea & rectal metronidazole & yes & yes & no \\
\hline 7 & $5-8$ & none & oral tinidazole & $\mathrm{n} / \mathrm{a}$ & yes & no \\
\hline
\end{tabular}

n/a not applicable 